\title{
INVENTORY CONTROL USING STATISTICS FORECASTING ON MANUFACTURE COMPANY
}

\author{
Rizki Tri Prasetio \\ Sistem Informasi \\ Universitas BSI \\ Jalan Sekolah Internasional No. 1-6 Antapani Bandung, 40282 \\ rizkitriprasetio@gmail.com
}

\begin{abstract}
Inventory Control is a main and the most crucial factor for company that can cause an efficient production process. A lot of research use different method to support inventory control. This research use several forecasting method such as, Nä̈ve Method, Exponential Smoothing, Exponential Smoothing with Trend, Moving Average, Weighted Moving Average and Linear Regression. Economic Order Quantity is used to calculate raw materials inventory. This research results suggest that company use Linear Regression as it has the smallest MAD and MSE of the six other methods. The company also has to implement Economic Order Quantity to minimalize loss profit due to excess inventory.
\end{abstract}

Keywords : Inventory Control, Forecasting Method, Economic Order Quantity

Abstrak - Pengendalian inventory merupakan salah satu faktor utama dan sangat penting bagi perusahaan karena sangat berpengaruh terhadap terciptanya proses produksi yang efisien. Banyak penelitian yang menggunakan beberapa metode guna mendukung pengendalian inventory. Penelitian ini menggunakan beberapa metode peramalan (forecasting method) diantaranya, Nä̈ve Method, Exponential Smoothing, Exponential Smoothing with Trend, Moving Average, Weighted Moving Average dan Linear Regression. Serta Economic Order Quantity (EOQ) yang digunakan untuk menghitung persediaan bahan baku yang dibutuhkan dalam proses produksi. Hasil penelitian menghasilkan bahwa metode peramalan Linear Regression memiliki tingkat kesalahan yang dihitung menggunakan MAD dan MSE paling kecil diantara 6 metode lainnya. Serta mengimplementasikan Economic Order Quantity untuk meminimalisir kerugian akibat kelebihan persediaan.

Kata Kunci : Pengendalian Persediaan, Metode Peramalan, Economic Order Quantity

\section{PENDAHULUAN}

Dunia industri semakin berkembang dan terus maju bersama dengan persaingan yang semakin ketat. Setiap perusahaan berusaha untuk meningkatkan produktivitas dan membuat produksi yang lebih efisien. Keberadaan perusahaan yang bergerak di bidang industri yang sama atau munculnya perusahaan - perusahaan baru menjadi salah satu faktor yang mengancam dan dapat menyebabkan penurunan keuntungan atau bahkan kehancuran bagi perusahaan tersebut. Oleh karena itu untuk menjaga perusahaan agar tetap bertahan, berbagai metode yang dibutuhkan untuk mendukung perkembangan perindustrian adalah meramalkan permintaan konsumen. Ini sangat penting karena meramalkan permintaan konsumen secara efektif akan mempengaruhi keuntungan perusahaan dengan cara menghindari penumpukan persediaan.

Sistem perencanaan inventory menjadi salah satu faktor yang paling penting dalam memenuhi kebutuhan konsumen dalam waktu yang tepat dan sesuai dengan permintaan, karena permintaan konsumen tidak selalu dapat di penuhi oleh kapasitas perusahaan dan sebagai hasilnya, keuntungan perusahaan akan menurun atau bahkan tidak membuat keuntungan sama sekali. Agar kegiatan produksi dapat berjalan dengan baik, ada kebutuhan akan komunikasi antara departemen produksi dan departemen inventory. Akan tetapi, departemen inventory harus memiliki kemampuan untuk menghitung dan 
memperkirakan tingkat persediaan untuk mencegah stok habis ketika dibutuhkan atau menghindari kelebihan stok sebelum pelanggan memesan. Untuk mengatasi masalah ini, perusahaan harus tahu mana teknik manajemen persediaan yang terbaik dan sesuai.

\section{KAJIAN LITERATUR}

\section{Inventory}

Definisi persediaan secara umum adalah aktiva perusahaan yang menempati posisi yang cukup penting dalam suatu perusahaan, baik itu perusahaan dagang maupun perusahaan industri. Menurut perspektif perusahaan dagang, Persediaan merupakan barang-barang yang dibeli oleh perusahaan dengan tujuan untuk dijual kembali dengan tanpa mengubah bentuk dan kualitas barang. Sedangkan menurut perspektif perusahaan industri, persediaan merupakan barang-barang yang dibeli oleh perusahaan dengan tujuan untuk diproses lebih lanjut menjadi barang jadi atau setengah jadi atau mungkin menjadi bahan baku bagi perusahaan lain. Kesimpulannya, persediaan merupakan sejumlah barang yang disediakan untuk memenuhi permintaan dari pelanggan. (Assauri, 2008)

\section{Raw Material}

Menurut Assauri (2008), Bahan baku merupakan barang berwujud (fisik) yang digunakan dalam proses produksi. Barang tersebut dapat diperoleh dari sumber daya alam atau dibeli dari pemasok atau perusahaan lain yang memproduksi bahan baku yang digunakan oleh pabrik-pabrik tertentu. Pabrik tersebut akan mengolah bahan tersebut, dan setelah menjalani beberapa proses produksi maka barang tersebut berubah menjadi barang jadi. Menurut Narafin (2007), bahan baku adalah bahan yang didefinisikan sebagai bahan yang membentuk sebuah entitas yang terpisah dari barang jadi. Bahan baku adalah bahan utama yang bertindak sebagai komponen utama dari suatu produk.

\section{Forecasting}

Ramalan adalah suatu situasi atau kondisi yang diperkirakan akan terjadi pada masa yang akan datang. Menurut Khotler (2004), peramalan menjadikan pengelolaan dari suatu variable di msa datang akan terlihat, sehingga mempermudah dalam perencanaan-perencanaan untuk periode yang akan datang. Menurut Assauri (2008), metode peramalan adalah cara memperkirakan secara kuantitatif apa yang akan terjadi pada masa depan, berdasarkan pada data yang relevan di masa lalu. Oleh karena metode peramalan didasarkan atas data yang relevan pada masa lalu, maka metode peramalan ini dipergunakan dalam peramalan yang obyektif.

\section{Nä̈ve Method}

Peramalan dengan metode ini diasumsikan bahwa periode sekarang adalah prediksi terbaik untuk masa depan. Peramalan dengan metode naïve untuk masing-masing periode mendekati observasi yang terdahulu. Ramalan dengan model naïve adalah ramalah yang kadang disebut juga dengan "ramalan tanpa perubahan". Karena ramalannya untuk setiap periode mendekati observasi yang terdahulu. (Hanke, 2005). Bentuk model naïve adalah :

$\gamma_{t+1}=\gamma_{t}$

Dimana $\gamma_{t+1}$ adalah ramalan yang dibuat pada waktu $t$ untuk waktu $t+1$.

\section{Exponential Smoothing}

Metode exponential smoothing adalah suatu prosedur yang secara terus menerus memperbaiki peramalan (smoothing) dengan merata-ratakan nilai masa lalu dari suatu data deret waktu dengan cara menurun (exponential). (Khotler, 2004). Bentuk model Exponential Smoothing adalah :

$S_{t}=\alpha X_{t}+(1-\alpha)\left(S_{t-1}+T_{t-1}\right)$

$S_{t}=$ Nilai pemulusan tunggal

$T_{t}=$ Pemulusan trend

$\beta=$ Konstanta dengan nilai antara 0 dan 1

\section{Exponential Smoothing with Trend}

Model exponential smoothing with trend merupakan salah satu analisis exponential smoothing yang menganalisa deret waktu, dan merupakan metode peramalan dengan memberi nilai pembobot pada serangkaian pengamatan sebelumnya untuk memprediksi masa depan. Bentuk model Exponential Smoothing with Trend adalah :

$T_{t}=\beta\left(S_{t}-S_{t-1}\right)+(1-\beta) T_{t-1}$

$S_{t}=$ Nilai pemulusan tunggal

$T_{t} \quad=$ Pemulusan trend

$\beta=$ Konstanta dengan nilai antara 0 dan 1 


\section{Moving Average}

Metode peramalan Moving Average merupakan peramalan yang didasarkan pada ratarata aritmatika yang didapatkan dari data pada masa lampau. (Dwaikat, 2008). Teknik peramalan permintaan menggunakan Moving Average diperkiran dengan menghitung rata-rata permintaan actual dari jumlah tertentu pada periode sebelumnya. Bentuk dari metode Moving Average adalah :

$$
A_{t}=\frac{D_{t}+D_{t-1}+D_{t-2}+\cdots+D_{t-N+1}}{N}
$$

Dimana $\mathrm{N}$ adalah jumlah periode dan $\mathrm{D}$ adalah jumlah permintaan.

\section{Weighted Moving Average}

Metode peramalah Weighted Moving Average merupakan peramalan lebih lanjut dari Moving Average dimana setiap deret waktu lampau diberikan bobot tertentu dan mungkin diberi bobot yang berbeda-beda (Dwaikat, 2008) bentuk dari metode Weighted Moving Average adalah :

$A_{t}=\frac{W_{1} D_{t}+W_{2} D_{t-1}+W_{3} D_{t-2}+\cdots+W_{N} D_{t-N+1}}{N}$

Dimana $\mathrm{N}$ adalah jumlah periode, $\mathrm{D}$ adalah jumlah permintaan dan $\mathrm{W}$ adalah bobot.

\section{Linear Regression}

Regresi adalah sebuah metode matematika untuk menggambarkan hubungan antara variablevariable. Kata linear menunjukan bahwa hubungannya adalah proporsional secara linear. Model regresi yang paling sederhana melibatkan sebuah variable tak bebeas dan sebuah variable bebas. Bentuk model Linear Regression adalah :

$\alpha=\frac{\sum y-\sum_{b} x}{n}$

$y=a+b x$

$\mathrm{x}=$ Periode saat ini

$\mathrm{n}=$ Total periode

\section{Pengukuran Relatif}

Pengukuran relative digunakan untuk mengetahui besar kesalahan sebuah peramalan. Besar kesalahan sebuah ramalan ini dapat diketahui dengan menghitung selisih antara nilai asli dengan nilai ramalan, yang biasa dikenal dengan nama error. Berikut ini merupakan beberapa cara pengukuran yang digunakan untuk mengetahui besarnya kesalahan yang dihasilkan oleh model peramalan :

\section{Mean Absolute Deviation (MAD)}

MAD merupakan ukuran utama dari kesalahan perkiraan dari seluruh model peramalan. Nilai error dihitung dengan membagi jumlah nilai absolut dari kesalahan perkiraan dengan jumlah periode

$M A D=\frac{\sum_{i=1}^{n}\left|Y_{i}-i\right|}{n}$

\section{Mean Squared Error (MSE)}

MSE merupakan ukuran kedua dari kesalahan perkiraan dari seluruh model peramalan. MSE adalah rata-rata kuadrat perbedaan antara nilai-nilai yang diamati dan diprediksi. Kelemahan dari menggunakan MSE adalah bahwa ia cenderung untuk menonjolkan penyimpangan besar karena istilah kuadrat.

$$
M S D=\frac{\sum_{i=1}^{n}\left|Y_{i}-i\right|^{2}}{n}
$$

\section{Mean Absolute Percentage Error (MAPE)}

Masalah dengan MAD dan MSE adalah bahwa nilai-nilai mereka bergantung pada besarnya item yang diperkirakan. Jika item yang diramalkan dalam ribuan, maka MAD dan MSE bisa sangat besar. Untuk menghindari masalah tersebut, kita dapat menggunakan MAPE yang merupakan rata-rata perbedaan mutlak antara nilai-niali yang diamati dan diramalkan.

$$
M A P E=\frac{\sum_{i=1}^{n}\left|P E_{i}\right|}{n}
$$

\section{Economic Order Quantity and Safety Stock}

Menurut Heizer dan Render (2001), Economic Order Quantity adalah jumlah yang paling ekonomis dari bahan untuk dipesan pada setiap pembelian yang dilakukan. Sebagai contoh, kebutuhan dasar perusahaan selama setahun berjumlah hingga 12.000 ton. Isu mengenai persediaan pada kenyataannya terdiri dari 2 pertanyaan, yaitu berapa banyak item untuk dipesan dan berapa banyak waktu yang harus diambil. Untuk menimimalisir biaya produksi.

Untuk menghitung EOQ, maka digunakan rumus sebagai berikut : 


$$
\begin{aligned}
& E O Q=\frac{\sqrt[2]{2(D)(S)}}{H} \\
& \text { EOQ } \quad=\text { Economic Order Quantity } \\
& \mathrm{D} \quad=\text { Jumlah Bahan Baku yang dibutuhkan } \\
& \text { per periode } \\
& \mathrm{S} \quad=\text { Biaya Bahan Baku } \\
& \mathrm{H} \quad=\text { Biaya bahan baku per periode }
\end{aligned}
$$

\section{METODE PENELITIAN}

\section{Jenis Penelitian}

Jenis penelitian yang dilakukan pada penelitian ini adalah penelitian eksperimen yang terbagi menjadi dua, yaitu eksperimen absolut dan eksperimen komparatif. Eksperimen absolut mengarah pada dampak yang dihasilkan dari eksperimen (Khotari, 2004). Dimana pada penelitian ini akan dilihat dampak dari penggunakan Economic Order Quantity (EOQ).

Eksperimen komparatif membandingkan beberapa metode peramalan diantaranya Naïve Method, Moving Average, Weighted Moving Average, Exponential Smoothing, Exponential Smoothing with Trend serta Linear Regression. Dimana pada penelitian ini akan dilihat metode peramalan mana yang memiliki tingkat error paling rendah.

\section{Variable Penelitian}

Terdapat dua variable pada penelitian ini yaitu, jumlah penjualan produk dan jumlah persediaan bahan baku. Untuk mendapatkan data dari variable tersebut digunakan data yang diperoleh dari PT. Yolita Jaya Indonesia.

\section{Metode Pemilihan Sampel}

Populasi dalam penelitian ini adalah data jumlah penjualan jas hujan serta data persediaan bahan baku pembuat jas hujan. Sedangkan sample yang digunakan dalam penelitian ini adalah data penjualan jas hujan dan data persediaan bahan baku untuk tipe JH Set mulai dari awal tahun 2012 hingga September 2013.

\section{Metode Pengumpulan Data}

Berdasarkan tipe pengumpulan data, terdapat dua jenis pengumpulan data yaitu, data primer dan data sekunder Data primer adalah data yang dikumpulkan pertama kali dan untuk melihat apa yang sesungguhnya terjadi, sedangkan data sekunder adalah data yang sebelumnya pernah dibuat oleh seseorang baik diterbitkan atau tidak (Kothari, 2004). Penelitian ini menggunakan sumber data yang diperoleh secara primer, yaitu data yang dikumpulkan pertama kali dari PT Yolita Jaya Indonesia.

\section{Instrumen Penelitian}

Pengolahan data variable-variable diatas menggunakan SPSS dan Microsoft Excel yang sudah di tambahkan dengan Macro menggunakan Visual Basic for Application sebagai instrument penelitian.

\section{Metode Analisis}

Data penjualan produk JH Set akan dianalisa menggunakan Nä̈ve Method, Moving Average, Weighted Moving Average, Exponential Smoothing, Exponential Smoothing with Trend serta Linear Regression untuk meramalkan penjualan produk JH Set dimasa depan. Lalu dilakukan evaluasi tingkat akurasi yang dihasilkan pada peramalan tersebut menggunakan MSE dan MAD untuk mengetahui metode peramalan paling tinggi tingkat akurasinya. Serta mengimplementasikan Economic Order Quantity untuk menghitung jumlah persediaan bahan baku yang dibutuhkan agar proses produksi dapat berjalan dengan efisien.

\section{PEMBAHASAN}

Berikut ini merupakan data penjualan jas hujan type JH Set dari awal 2012 hingga September 2013 :

Tabel 1

Data Penjualan Jas Hujan JH Set 2012-2013

\begin{tabular}{lr}
\hline Bulan & Jumlah Item \\
\hline Januari & 1200 \\
\hline Februari & 1000 \\
\hline Maret & 1000 \\
\hline April & 950 \\
\hline Mei & 1150 \\
\hline Juni & 1000 \\
\hline Juli & 800 \\
\hline Agustus & 1100 \\
\hline September & 900 \\
\hline Oktober & 1000 \\
\hline November & 1250 \\
\hline Desember & 1170 \\
\hline Januari & 1150 \\
\hline Februari & 900 \\
\hline
\end{tabular}




\section{Lanjutan \\ Tabel 1}

Data Penjualan Jas Hujan JH Set 2012-2013

\begin{tabular}{lr}
\hline \multicolumn{1}{c}{ Bulan } & Jumlah Item \\
\hline Maret & 850 \\
\hline April & 920 \\
\hline Mei & 1000 \\
\hline Juni & 1150 \\
\hline Juli & 980 \\
\hline Agustus & 1250 \\
\hline September & 1175 \\
\hline
\end{tabular}

Sumber : Hasil Pengumpulan Data (2014)

Peramalan untuk data diatas menggunakan SPSS dan Microsoft Excel yang sudah ditambahkan dengan macro. Beberapa metode yang digunakan yaitu, Naïve Method (NM), Moving Average (MA), Weighted Moving Average (WMA), Exponential Smoothing (ES), Exponential Smoothing with Trend (ESWT) dan Liner Regression (LR).

Tabel 2

Hasil Peramalan Data Penjualan Oktober 2013

\begin{tabular}{lccc}
\hline Metode & MAD & MSE & Forecast \\
\hline NM & 143.25 & $28,026.25$ & $1,175.00$ \\
\hline MA & 131.94 & $24,611.27$ & $1,135.00$ \\
\hline WMA & 128.00 & $23,561.11$ & $1,158.50$ \\
\hline ES & 132.89 & $23,037.36$ & $1,112.21$ \\
\hline ESWT & 139.25 & $25,637.46$ & $1,135.95$ \\
\hline LR & 112.63 & $16,635.14$ & $1,074.19$ \\
\hline
\end{tabular}

Sumber : Hasil Pemrosesan Data (2014)

Hasil yang didapatkan dari pemrosesan data diatas menunjukan bahwa Linear Regression memiliki nilai MAD dan MSE paling rendah diantara metodel peramalan lainnya. Sehingga dapat ditarik kesimpulan bahwa Linear Regression memiliki akurasi peramalan paling tinggi.

Setelah melakukan peramalan pada jumlah penjualan produk, maka penelitian dilanjutkan dengan mengkalkulasikan persediaan bahan baku yang dibutuhkan. Ini sangat penting bagi perusahaan untuk menjaga agar produksi tetap berjalan dengan efisien dan memenuhi kebutuhan konsumen.
Tabel 3

Data Persediaan Bahan Baku (PVC)

\begin{tabular}{ll}
\hline Demand & $322,500 \mathrm{Kg}$ \\
\hline PVC Price per Kg & $\mathrm{Rp} .9,800 / \mathrm{Kg}$ \\
\hline Shipping Cost & $\mathrm{Rp} .12,000,000$ \\
\hline Lead time & 12 Days \\
\hline Inventory Carrying Cost & $\mathrm{Rp} .1,000$ \\
\hline Number of Working Days & 300 Days \\
\hline Safety Stock & $50,000 \mathrm{Kg}$ \\
\hline \multicolumn{2}{l}{ Sumber : Hasil Pemrosesan Data (2014) }
\end{tabular}

$$
\begin{aligned}
& \mathrm{EOQ}=\frac{\sqrt[2]{2(\mathrm{D})(\mathrm{S})}}{\mathrm{H}} \\
& \mathrm{EOQ}=\frac{\sqrt[2]{2(322,500)(12,000,000)}}{1000} \\
& \mathrm{EOQ}=87,977.3 \mathrm{Kg} \\
& \mathrm{EOQ}=\mathbf{8 7}, \mathbf{9 7} \mathrm{Ton}
\end{aligned}
$$

Average Inventory $=\frac{\mathrm{EOQ}}{2}$

Average Inventory $=\frac{87,977.3 \mathrm{Kg}}{2}$

Average Inventory $=43,988.65 \mathrm{Kg}$

Average Inventory $=43,98$ Ton

$\begin{aligned} \text { Order Frequency } & =\frac{\text { Demand }}{\mathrm{EOQ}} \\ \text { Order Frequency } & =\frac{322,500 \mathrm{Kg}}{87,977.3 \mathrm{Kg}} \\ \text { Order Frequency } & =\mathbf{3 . 6 6 \text { times }} \\ \text { Annual Setup Cost } & =\frac{(\text { Demand) (Shipping Cost) }}{\mathrm{EOQ}}\end{aligned}$

Annual Setup Cost $=\frac{(322,500)(12,000,000)}{87,977.3}$

Annual Setup Cost $=$ Rp. 43, 988, 619.791

Annual Holding Cost $=\frac{(\text { EOQ })(\text { Inventory Carrying Cost })}{2}$

Annual Holding Cost $=\frac{(87,977.3)(1,000)}{2}$

Annual Holding Cost $=$ Rp. 43, 988, 650

Total Unit Cost $=($ Unit Cost $)($ Demand $)$

Total Unit Cost $=($ Rp. 9,800 $)(322,500 \mathrm{Kg})$

Total Unit Cost $=$ Rp. 3, 160, 500, 000

Total Cost $=($ Total Unit Cost $)+($ Setup Cost $)$ + (Holding Cost)

Total Cost $=($ Rp. $3,160,500,000)$

$$
+ \text { (Rp. 43,988,619.791) }
$$$$
+ \text { (Rp. 43,988,650) }
$$

Total Cost $=$ Rp. 3, 248, 477, 269.791 
Daily Demand $=$ Forecast Demand

Daily Demand $=1,075 \mathrm{Kg}$

Daily Demand $=1.075$ Ton

Reorder Point

$=$ Safety Stock $\{($ Lead Time)(Daily Demand $)\}$

Reorder Point

$=5,000 \mathrm{Kg}\{(12$ Days $)(1,075 \mathrm{Kg})\}$

Reorder Point $=645,000 \mathrm{Kg}$

Reorder Point $=\mathbf{6 4 5}$ Ton

Dapat disimpulkan dari kedua perhitungan diatas bahwa agar jumlah bahan baku (PVC) yang digunakan dalam pembuatan jas hujan type JH Set menjadi ekonomis dan efisien maka dibutuhkan $87,977 \mathrm{Kg}$ atau 87,98 Ton. Jumlah tersebut harus dibagi menjadi 3,66 permintaan dalam setahun untuk memenuhi kebutuhan PVC. Pembelian bahan baku ulang dilakukan apabila jumlah PVC turuh dibawah 645 Ton.

Perusahaan membutuhkan sebanya $1,075 \mathrm{Kg}$ atau 1.075 Ton PVC untuk produksi harian. Setiap kali ada pesanan, perusahaan harus membayar biaya 43,998,619 rupiah sebagai biaya pembelian bahan baku dan 43,988,650 rupiah sebagai biaya produksi. Jumlah biaya yang dikeluarkan untuk memenuhi biaya produksi jas hujan tipe JH Set adalah 3,248,477,269 Rupiah, sedangkan biaya untuk pembelian PVC sendiri sebesar 3,160,500,000 Rupiah.

\section{PENUTUP}

\section{Kesimpulan}

Kesimpulan yang didapat dari hasil penelitian ini adalah :

1. Berdasrkan perkiraan tingkat permintaan untuk bulan Oktober 2013 yang dihitung menggunakan SPSS dan Microsoft Excel dengan menggunakan enam metode peramalan, kelas bahwa metode terbaik untuk menentukan tingkat permintaan terhadap produk adalah metode Linear Regression karena memiliki nilai MAD dan MSE paling rendah diantara metode peramalan lainnya.

2. Setelah mendapatkan hasil perkiraan tingkat permintaan untuk bulan Oktober 2013, maka dilanjutkan dengan perhitungan Economic Order Quantity bagi perusahaan untuk membeli bahan baku utama yaitu PVC. PVC harus dibeli dalam jumlah yang tepat agar proses produksi dapat berjalan dengan baik dan efisien.

\section{REFERENSI}

[1] Assauri, Sofjan. 2008. Manajemen Produksi dan Operasi. Edisi Revisi Fakultas Universitas Indonesia, Jakarta.

[2] Assauri, S. 2004. Teknik dan Metode Peramalan Penerapannya dalam Ekonomi dan Dunia Usaha. UI Press. Jakarta.

[3] Chase, Jacob Aquilano. (2004). Operation Management for Competitive Advantage, Tenth Edition. McGraw Hill.

[4] Gaspersz, Vincent. (2005). Production Planning and Inventory Control Berdasarkan Pendekatan

[5] Sistem Terintergrasi MRP II dan JIT Menuju Manufacturing 21. PT. Gramedia Pustaka Utama, Jakarta.

[6] Heizer, Jay, Barry Rander. (2001). Operation Management Sixth Edition. New Jersey:Prentice Hall.

[7] Heizer, J., Render, B. (2001). Prinsip prinsip Manajemen Operasi. Jakarta: Salemba Empat.

[8] Henke, E. dan Reitch, G., 1995. Bussiness Forecasting. Sixth Edition, prentice Hall, New jersey

[9] Khotler, P. 1994. Marketing Management : Analysis Planning Implementations and Control. Eight Edition. Prentice Hall.Inc.New Jersey.

[10] Makridakis, S., Wright, S.C.W.,dan Mc Gee V.1999. Alih Bahasa Suminto, H,Ir. Metode dan Aplikasi Peramalan. Edisi Kedua.Binaputra Aksara. Jakarta.

[11] Trihendradi, C. 2005. SPSS 13 : Step By Step Analysis Data Statistik. Andi Offset Yogyakarta.

[12] Nachrowi D., Hardius. (2004). Teknik Pengambilan Keputusan. Grasindo. Jakarta.

[13]Narafin, M. (2007). Penganggaran Perusahaan. Salemba Empat, Jakarta.

[14] Nahmias, B. (2001). Production and Operation Analysis Fourth Edition. Mc.Graw Hill.

[15]Nasution, Arman Hakim. (2003). Perencanaan dan Pengendalian Produksi. Edisi Pertama Cetakan Ke-dua. Guna Widya, Surabaya.

[16] Dwaikat, Nidal. 2009. Production Planning \&Inventory Control. An-Najah National University : Industrial Engineering Department

[17] Rangkuti, Freedy. (2004). Manajemen Persediaan, Jakarta: PT.Raja Grafindo Persada. 
[18] Sarjono, H; Agustina, Y. and Pujadi, A. (2008). Analisis Peramalan Penjualan pada PT Multi Megah Mandiri Tahun. Management Expose Volume 8 No 17. September.

\section{Tentang Penulis}

Rizki Tri Prasetio, Lahir di Bandung, 11 Desember 1989, Lulusan S1 Sistem Informasi Universitas BSI Bandung, saat ini aktif sebagai Instruktur di Universitas BSI Bandung. 